\title{
Connecting Water Resources across Political Borders: A Pearl River Delta Special Ecological Area
}

\author{
Jason F. Carlow, Ivan Valin, Stefan Al
}

\begin{abstract}
Situated between several interdependent political and economic zones of southern China's Pearl River Delta, the Pearl River Delta Special Ecological Area (PRD SEA) project explores the possibility that regional administrative boundaries could be softened and redrawn along ecological boundaries. With the advent of global sea level rise and its impact on the fragile fresh water ecology and huge population of the Pearl River Delta, the project proposes novel ways to share fresh water and wastewater across political zones to better administer and profit from the distribution of water resources.

Climate change, urbanization, and pollution from industrial and agricultural development threaten the steady supply of fresh water to the Pearl River Delta and its cities, while population growth in the region only increases demand. At the same time, Hong Kong, Macau and Shenzhen's increasing economic, political and cultural interdependency presents the possibility to tackle these challenges holistically. Layering a regional water resource infrastructure onto existing and new industrial, residential, agricultural and transportation armatures would transcend borders and create new economic markets through ecologically sustainable practices.
\end{abstract}

Keywords: delta ecology, ecological infrastructure, Pearl River Delta, resilient infrastructure, wastewater treatment

Situated between several interdependent political and economic zones of southern China's Pearl River Delta, the Pearl River Delta Special Ecological Area (PRD SEA) project explores the possibility that regional administrative 
boundaries could be softened and redrawn along ecological boundaries. With the advent of global sea level rise and its impact on the fragile fresh water ecology and huge population of the Pearl River Delta, the project proposes novel ways to share fresh water and wastewater across political zones to better administer and profit from the distribution of water resources.

The PRD SEA proposal was one of six projects initiated and funded by the curators of a special exhibition, entitled Counterpart Cities, within the 2011 Shenzhen/Hong Kong Bi-City Biennale of Architecture and Urbanism. Counterpart Cities curators Jonathan Solomon and Dorothy Tang designed the exhibition to raise local and international awareness of the challenges and opportunities that climate change and human intervention will bring to the unique ecology of the Hong Kong and Shenzhen region. ${ }^{1}$ The exhibition brought together multidisciplinary design teams from both sides of the Hong Kong and Shenzhen border to research challenges and propose solutions to systemic changes in the fresh water infrastructure, shore ecology, and port systems of the two cities. The PRD SEA project team worked to address the problems of fresh water infrastructure. Rather than focusing narrowly on the Hong Kong and Shenzhen territories, the PRD SEA defined the project site more broadly to look at the ecosystem and infrastructure of the larger Pearl River Delta region.

Climate change, urbanization, and industrialization threaten the steady provision of fresh water to the Pearl River Delta and its cities. Most of Hong Kong and Shenzhen's fresh water comes from the Dong River, which is impacted by increasing salt-water intrusion because of decreased stream flows and higher sea levels, pollution from industrial and agricultural development and extreme conditions of drought and rain as a result of climate change. On top of environmental issues, high population and GDP growth rates will continue to pressure the demand for fresh water. However, a series of opportunities arise within this dynamic context as well. China's planned political reunification with Hong Kong in 2047 and Macau in 2049 presents the possibility to tackle environmental threats holistically and to exploit the interconnectedness and interdependencies in the Delta landscape related to the allocation of potable water. New high-profile infrastructure projects such as the $50 \mathrm{~km}$ [31 mi.] Hong KongZhuhai-Macau Bridge (HZMB), allow for potential synergies with the everyday infrastructures like the fresh water production, supply, and storage infrastructures across the region.

The Pearl River Delta, that low-lying basin born of sediment carried from inner China, is a constantly shifting environment of agriculture, critical wetland and lowland habitat, and - recently - nearly continuous urbanized landscapes. As this region consolidates through infrastructural planning and economic development, we propose that an "ecological" term is needed: the Pearl River Delta Special Ecological Area.

The PRD SEA is a zone of interconnected water resources encircling the 
estuary (Fig. 1). To address the challenges of fresh water provision and wastewater treatment in the region, the PRD SEA proposes a zone of interconnected water resources. The proposal adopts four water resource strategies: move from a centralized to a decentralized system of water supply and recovery; link independent systems to enable resource sharing; piggyback new systems on defunct, existing and planned infrastructure; and finally treat wastewater as a resource.

The proposal imagines a fundamental realignment of water resources from a centrally managed source-to-user system, to one that is dispersed and interdependent, relying on a distributed, user-as-source network. Traditionally, the collection and storage of fresh water, the distribution of potable water, and treatment of resulting wastewater are found in independent systems. Within the PRD SEA, systems would be networked into a continuous loop of fresh water and treated wastewater conduits, allowing shortage and surplus in local systems to be absorbed and resources between the municipalities of Hong Kong, Shenzhen, Dongguan, Guangzhou, Zhongshan, Zhuhai and Macau to be shared. Along its length, the Loop could store water like a reservoir, but distribute it like a pipe. Effectively, the network is a water equivalent to the "smart" electricity grid. This integrated system includes water distribution networks, water reservoirs, wastewater treatment plants, desalination plants, levee systems, and constructed wetlands. They will occupy parts of future and existing infrastructure, such as the new Hong Kong-Zhuhai-Macau Bridge, existing

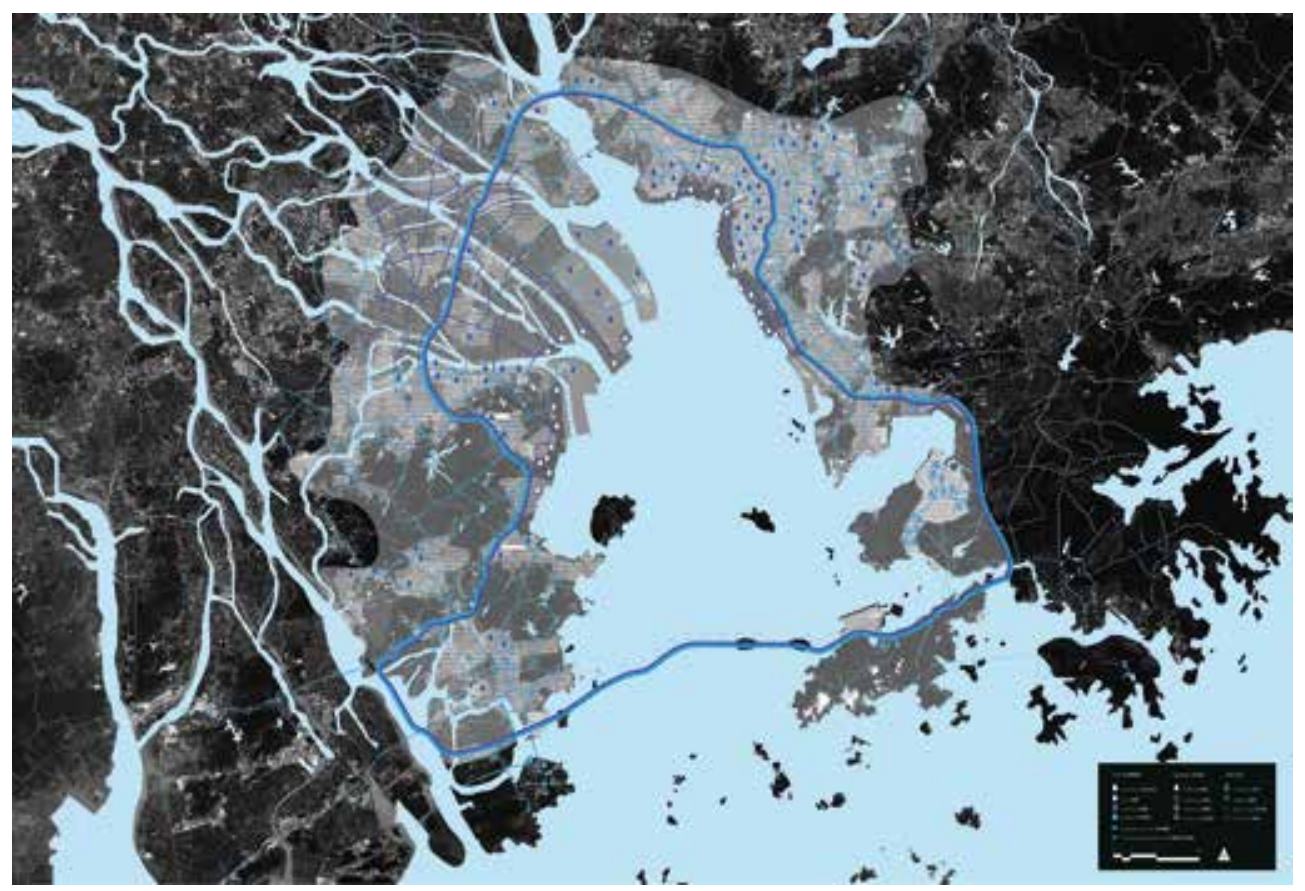

Figure 1. A masterplan of the Pearl River Delta Special Ecological Area depicts the water supply loop connecting various resources distributed throughout the various political entities of China's Pearl River Delta. 
highways, dykes, pipelines, water reservoirs, factory complexes and residential estates. This unlocks a number of synergies. For instance, water reservoirs will not only store water but can also be turned into pumped storage-hydroelectric power facilities that power the new water distribution network. Constructed wetlands will not only treat water but will also environmentally remediate contaminated land, serve as recreational space, and increase biodiversity.

Wastewater, no longer simply a waste, is reclaimed and distributed as a resource for sustaining development and reducing demand for treated fresh water. While such water-reuse strategies are best practice at the site/ development scale, they are not often harnessed as a larger infrastructure. Considering that a large percentage of buildings in Hong Kong use seawater for toilet flushing and water-cooling, the city will be able to export treated wastewater that could be distributed to industrial areas on the east side of the Pearl River estuary. At the same time, fresh water flowing from constructed wetlands on the east side of the Pearl River Delta or from new desalination facilities along the HZMB could be distributed to Hong Kong. The project is unique in that it looks at not only ecological systems but architectural, economic, transportation and political systems for opportunities to integrate into a comprehensive infrastructure. Layering a regional water resource infrastructure onto existing and planned industrial, residential, agricultural and transportation armatures would transcend borders and create new economic markets through ecologically sustainable practices.

\section{PROJECT COMPONENTS}

\section{Residential Zones: Vertical Wastewater Treatment}

Hong Kong's extensive new town developments and their counterparts in the PRD areas are largely residential developments. The housing estates and private developments commonly feature high-rise residential towers. These towers hold enormous potential for providing large vertical surfaces that can be used for water filtration and treatment. This natural, gravitydriven process will reduce the burden on costly new centralized systems as population centers expand and grow in the coming century. Treating wastewater at the source will help to preserve limited fresh water resources for drinking.

The vertical water treatment system can be designed in parallel with new buildings, which are increasingly incorporating modular BIM technologies. Likewise, upgrades can be integrated into facade systems of existing buildings as part of regular upgrading works. Since plumbing systems in Hong Kong and Shenzhen are generally located on the exteriors of facades, the potential for onsite treatment is relatively simple and cost effective, as they required no structural alterations. In addition to providing 
treatment of wastewater into reusable grey water, the facade systems would sustain planting, establishing vertical green zones on facades to provide air-pollution absorption, solar shading and passive cooling on south and western facades (Fig. 2). The overall system will reduce energy costs through decreasing air-conditioning costs and reduce overall fresh water consumption. Housing estates with vertical treatment systems plug into the overall PRD SEA loop to contribute this pre-treated wastewater for use in areas needed throughout the delta. Incentives for facade treatment systems may include reduced taxes or increased Gross Floor Area (GFA)

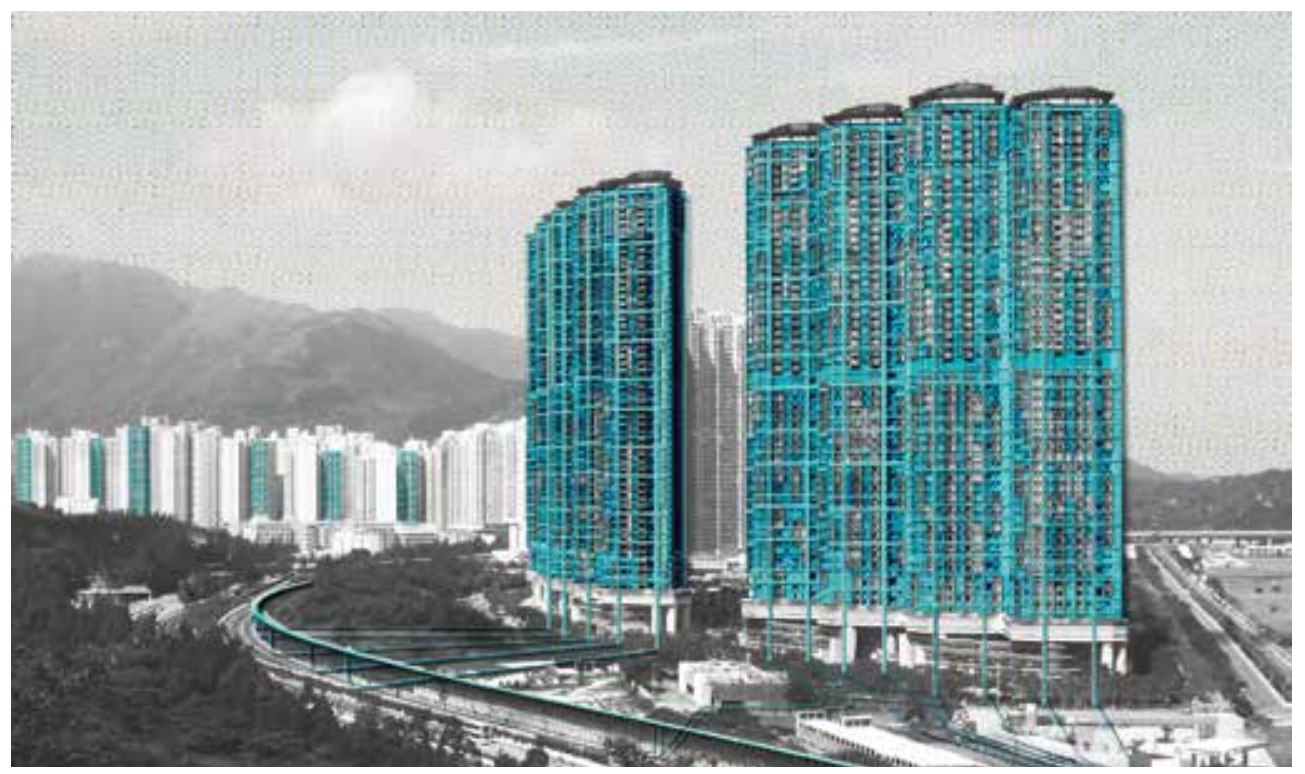

Figure 2. Wastewater collection and vertical water treatment systems are layered onto the facades of residential towers to take advantage of gravity-driven purification systems.

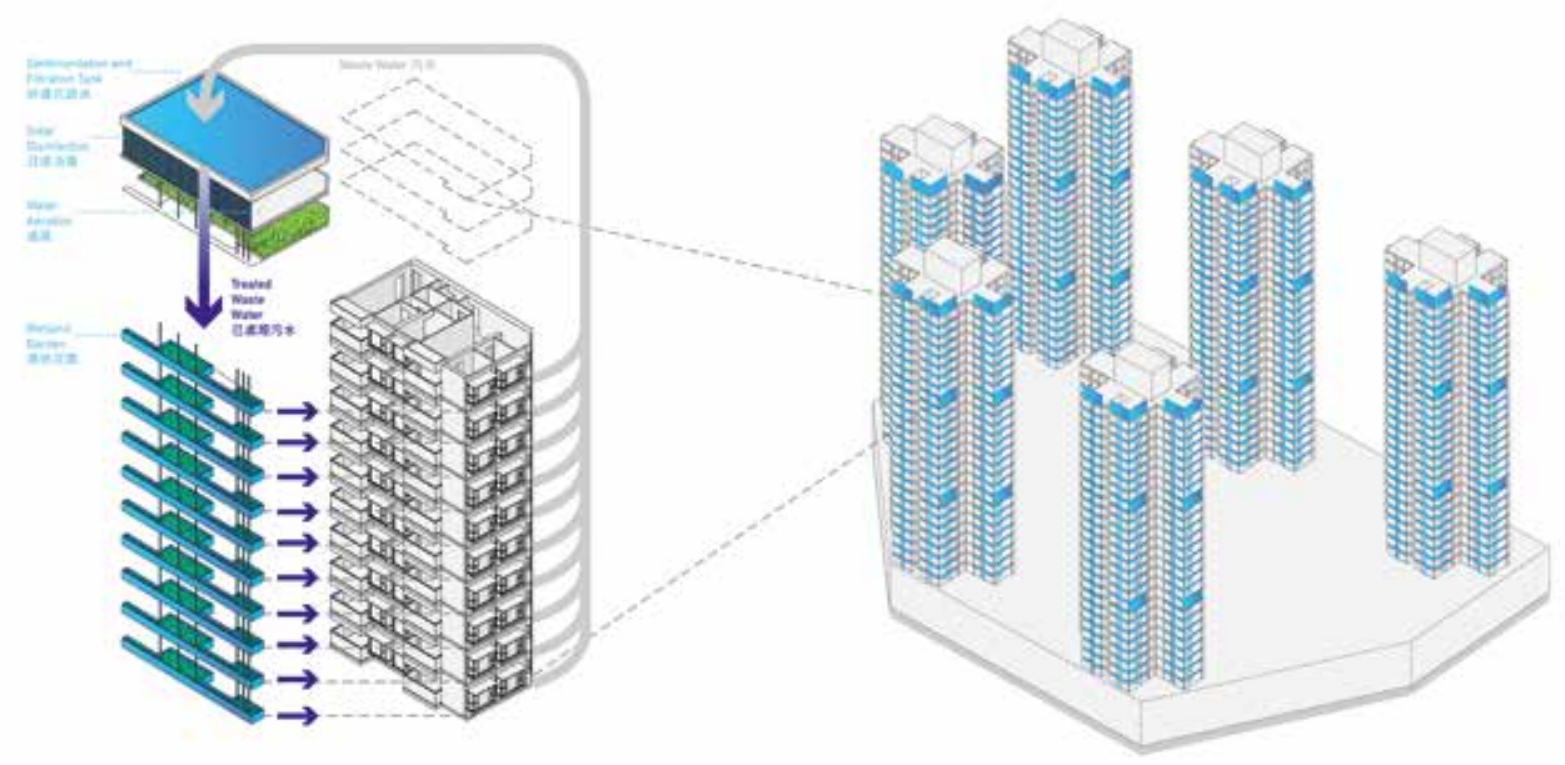

Figure 3. This diagram illustrates the various components of vertical wastewater treatment systems attached to residential tower facades. 
allowances for developers. Vertical wastewater treatment systems feature slow, gravity-driven flow. Wastewater is pumped to storage facilities on the top of the building where initial sedimentation occurs. From there, water moves down through a series of sand filters, aeration systems and solar disinfection zones and is ultimately captured in the PRD SEA wastewater loop (Fig. 3).

\section{Industrial Zones: Phased Water Remediation}

The northern sector of the Pearl River Delta is an expansive zone of industrial sprawl known informally as the factory of the world. It is a landscape of making and distribution driven by the Special Economic Zone (SEZ)/Special Administrative Region (SAR) pairing of Shenzhen and Hong Kong and the Pearl River Delta itself: a resource rich landscape with direct connections to the world's markets. As urbanization in the PRD continues to expand and develop, the region's legacy serves as an obstacle to sustainable growth. Vast swaths of industrial and manufacturing sites surrounding cities like Guangzhou, Dongguan, and Shenzhen are brownfields with extremely contaminated soil and groundwater. These sites are a threat to human health and an impediment to sustainable urban growth as developers choose instead to build on less capitally intensive agricultural or green-fields. Furthermore, these sites - many of which are located in low-lying areas alongside waterways in the Delta - pose a threat to the environment as sea-levels rise to predicted levels. Their contaminated soils will leech into the water and prevent the formation of ideal intertidal habitat.

By incorporating these sites into the SEA's greater network of water cleaning and distribution infrastructures, these sites can once again become vital and productive landscapes enabling safe and sustainable urban environment.

The strategy for the first phase for the industrial zones is centered on the reuse of outdated manufacturing districts. Abandoned factories throughout the industrial zones of Shenzhen, Guangzhou and Dongguan may sit idle but remain as physical collections of large structures connected to a robust and multi-layered infrastructure of water supply, electricity, and transportation that can be leveraged in the first step of their transformation. The need for wastewater treatment in the PRD is immediate and growing. Most of the waterways are already polluted to unacceptable levels. Small to medium wastewater treatment cells might be inserted into these abandoned spaces to meet some of this immediate demand, reusing as much of the structural and distribution infrastructures as possible to insure a rapid deployment (Fig 4).

The second phase of the proposal for the industrial areas involves remediation. Working first in conjunction with the wastewater treatment 
cells, landscaped components such as settling ponds, living machines, and pond wetlands can be implemented to pre-treat or polish water coming into or leaving the treatment cells (Fig. 5). These natural systems will reduce the energy demands and costs of the treatment plans while increasing their flow-rates. Individual species within these productive ecologies can be chosen for their capacity for phyto-transformation and phyto-stimulation to take place and directly improve the quality of the land and groundwater of the site. Gradually, the intensive wastewater treatment processes could be phased out by more extensive natural systems and living machines.

As sites are remediated, they can then be safely developed for residential or commercial use, thus funding the next round of cleanup in other regions within the PRD SEA.
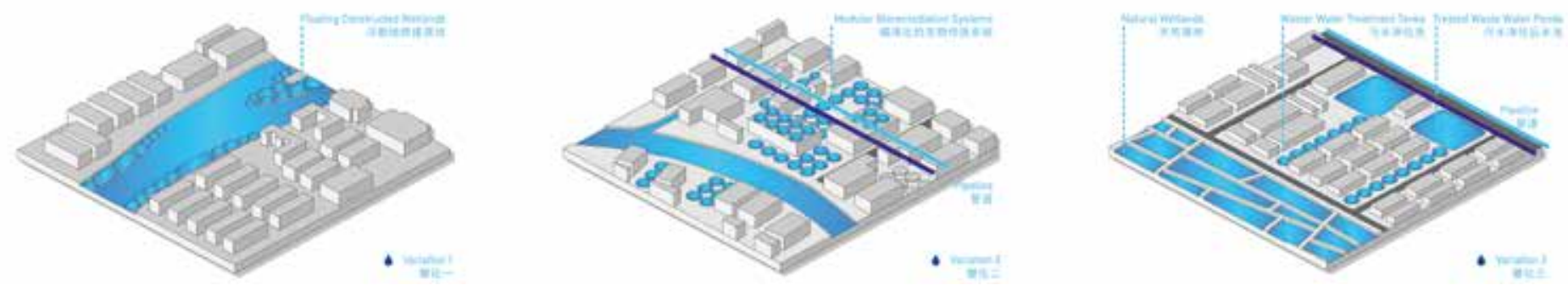

Figure 4. Variations of wastewater treatment and ground remediation systems layered onto and between existing industrial zones of the Pearl River Delta.

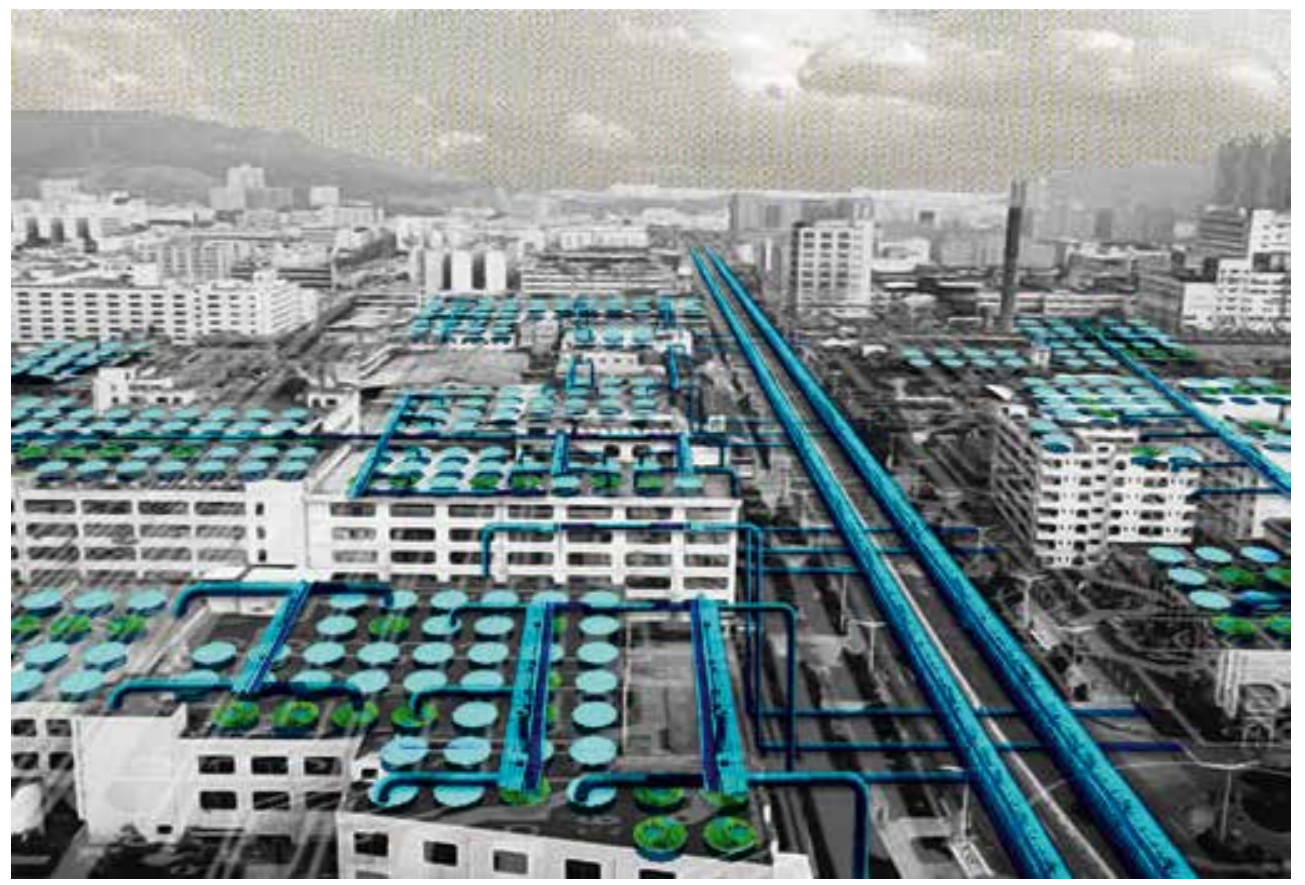

Figure 5. An illustration of how wastewater treatment systems may be integrated into Pearl River Delta industrial districts. 


\section{Levee Network: Coastal Farming and Filtration}

The lands most threatened by sea level rise and rapid urbanization in the Pearl River Delta are the low-lying agricultural areas that ring the estuary, especially along the less developed western edges. Reclaimed from the mud flats and marshes of the delta, these landscapes are important sites of food production and a critical habitat for endemic animal species and migrating birds. Squeezed between tidal zones and expanding urbanization, agricultural zones and remaining habitat fragments will shrink and eventually disappear. Also lost will be the buffering function of these wide swaths of farmland, lowland and wetland - replaced by seawalls, floodgates, and storm sewers, as sea levels rise. In re-imagining our potable water cycle, we must consider this important, if unrecognized, link in the system. We propose to integrate landscape-planning strategies into the SEA's water network by protecting and reinforcing these sites as zones of important ecological services such as water treatment and flood protection.

The levee is the most critical element in the delta landscape. In affording the reclamation of land behind, the raised mounds also function as a road network while their steep slopes are narrow shelves for littoral plants and animals to survive. Yet levees are often weak and ad-hoc, poorly maintained and monitored, and implemented without any larger organizing framework with which to capture the advantages of scale and distribution. Agricultural and low-lying areas within the SEA will be augmented and maintained as a single system. The role of flood protection and food production will be strengthened, while functions of habitat, recreation, and water filtration are greatly expanded (Fig. 6). Working with existing patterns of land use and hydrology, the edge will be constantly surveyed and evaluated to ensure a best fit for an ever-changing environment. The project proposes that the components of a levee face, backslope and crown, are applied at a regional scale to construct a more resilient landscape.
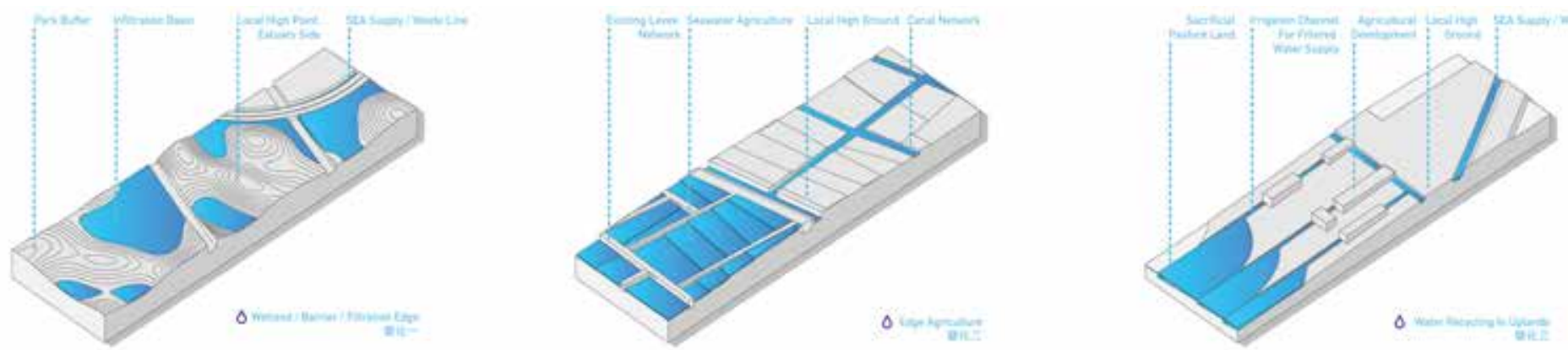

Figure 6. Diagrams for three strategies of flood protection and water treatment to be integrated into coastal agricultural areas of the Pearl River Delta (PRD). 


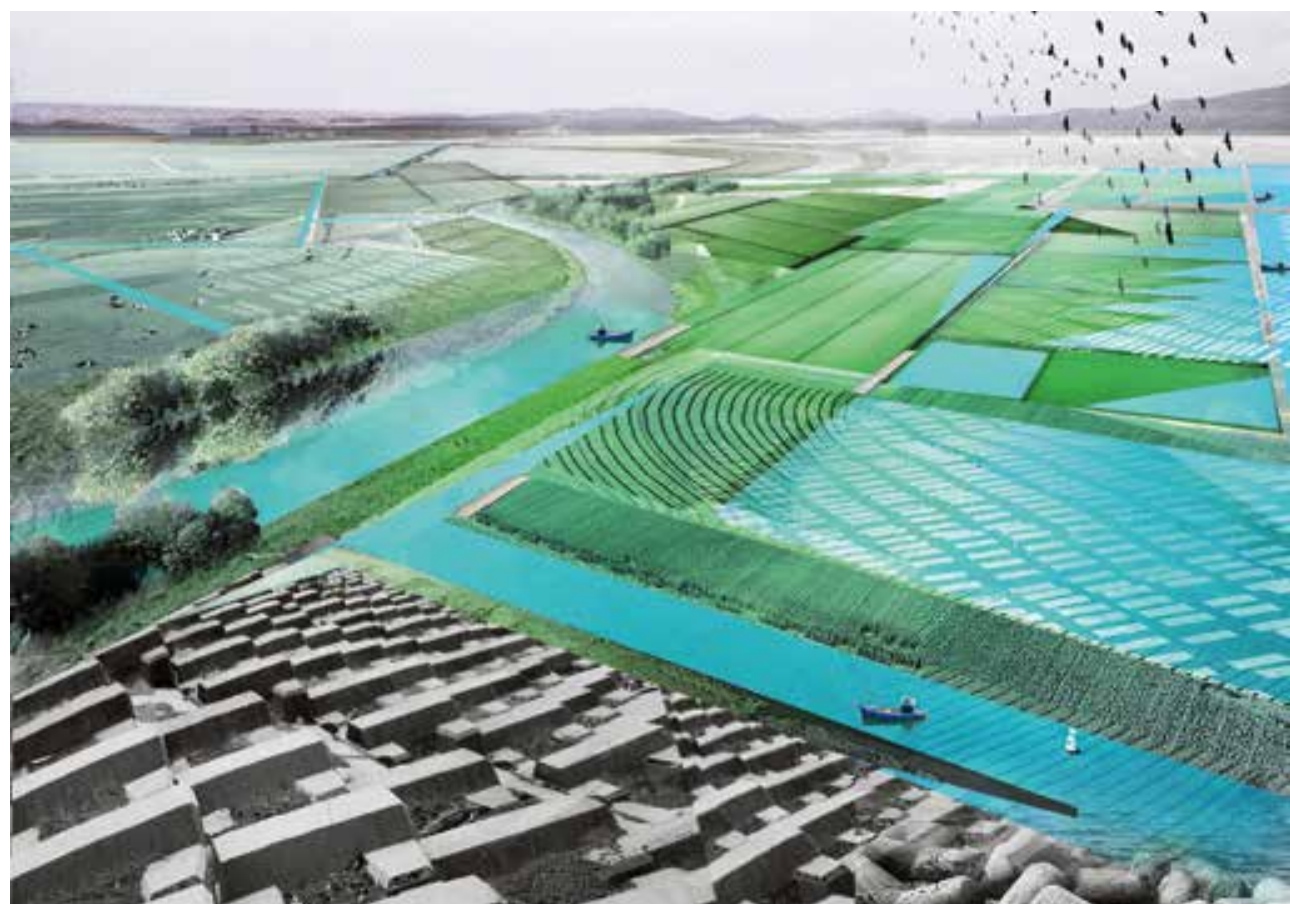

Figure 7. A rendering of various flood protection and water treatment systems to be integrated into coastal agricultural areas of the PRD.

The backslope is composed of protected agricultural land within a matrix of water filtration zones. These terraces are stacked sequentially to induce natural water flow across their surfaces for both agricultural and ecological benefit. The high point, or crown, that keeps out the highest waters, is organized around the most critical regional infrastructures and the new water delivery system proposed at the heart of the SEA. This wide ridge will be too broad for under-seepage or overturning associated with typical levees, and breaches will cease to be a possibility. The expanded water-free zone will also allow more possibilities for development, and the safe, waterside land can be leveraged as a funding tool. Levee faces, fronting on the tidally-effected estuary waters, will benefit from planned linkages to expand and connect tidal marshes with intervening halophytic agriculture or recreational development (Fig. 7).

\section{HZMB: Linear Desalination}

The Hong Kong-Zhuhai-Macau Bridge is a $50 \mathrm{~km}$-long [31 mi.] bridge and tunnel system being built to link the east and west sides of the Pearl River Delta. The level of investment necessary to complete the bridge is so large that it makes little sense for the bridge to act as only a vehicular link. This proposal for the HZMB weaves new water resource infrastructure onto the viaduct in the form of a linear desalination plant and new water storage facilities (Fig. 8). The bridge is an integral part of the PRD SEA water resource loop for the connectivity it provides and its proximity to seawater. 

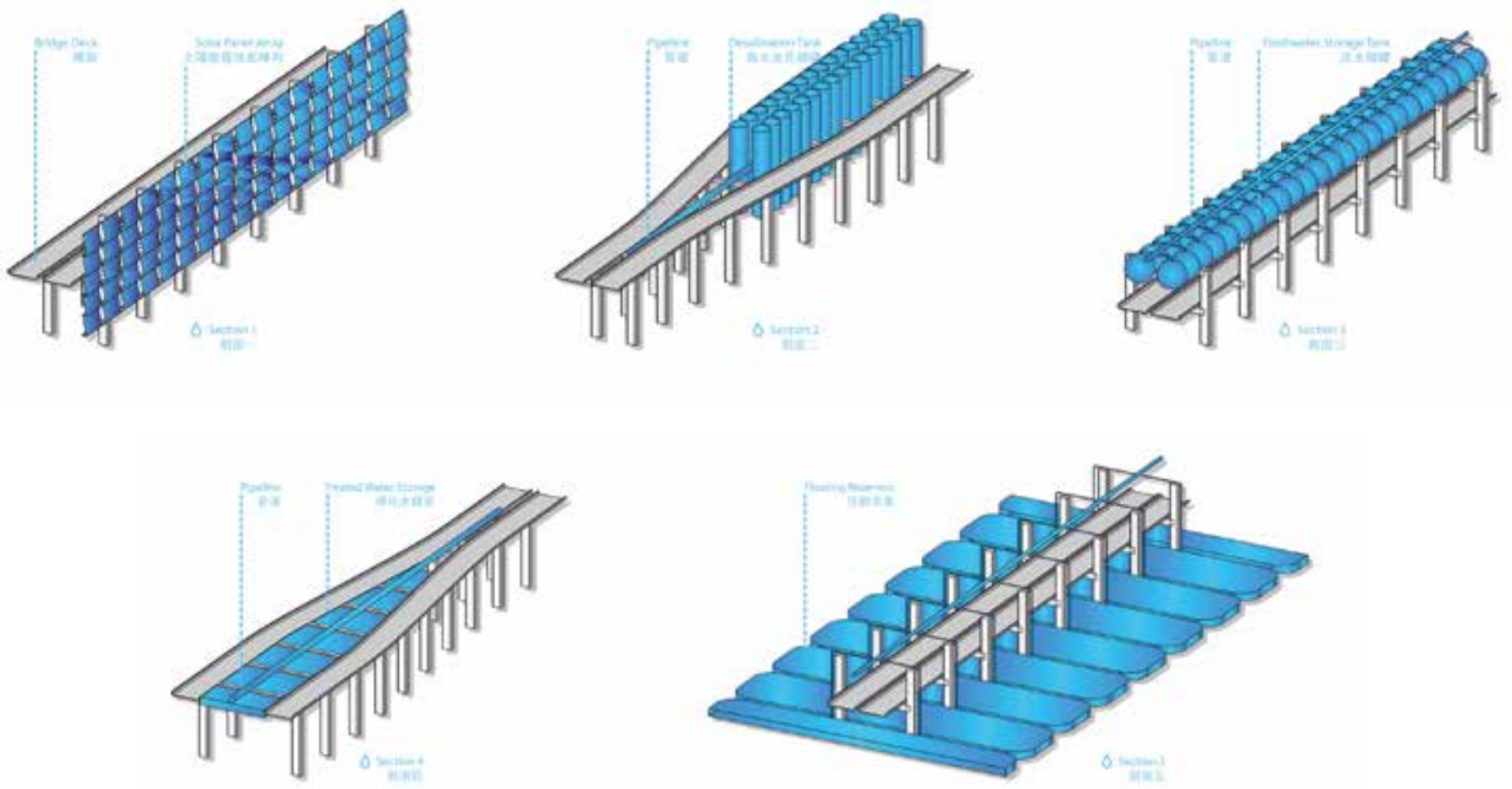

Figure 8. A diagram of five components of energy generation and water desalination systems built onto the Hong Kong-Zhuhai-Macau Bridge (HZMB).

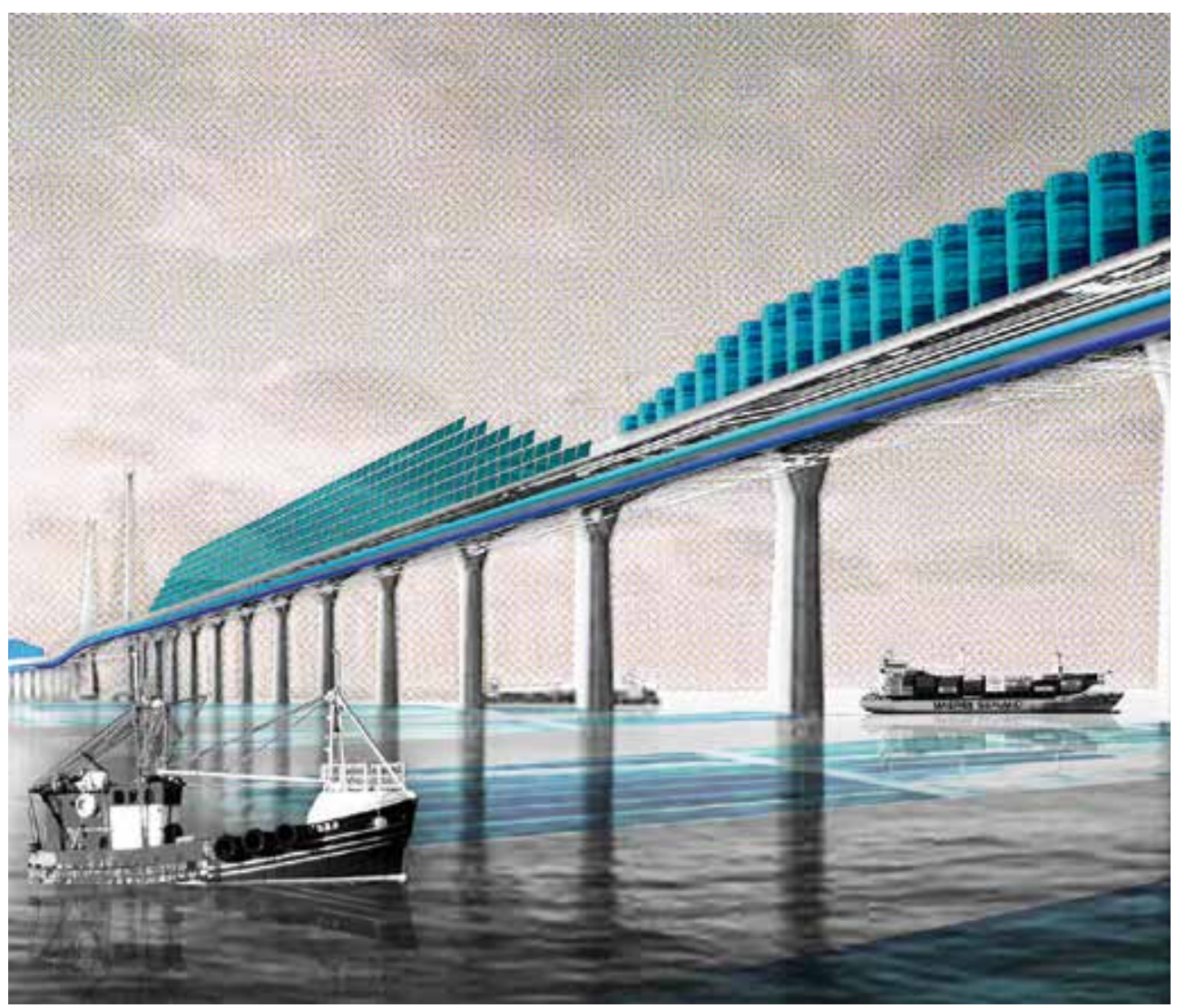

Figure 9. A rendering of the $\mathrm{HZMB}$ with linear arrays of solar panels and water storage tanks. 
The proposal makes use of the bridge deck to hold water tanks and desalination equipment that feed fresh water directly into the SEA loop. The bridge structure supports the pipelines for potable and treated wastewater along its length (Fig. 9). The structure also supports solar panel arrays and a pumped water hydroelectric system. These systems for creating cleaner energy are positioned to collect electricity to power the overall loop, while excess energy can be fed back into the regional electrical grid. Newly built, artificial islands at either end of the HMZB tunnel will be utilized for larger scale parts of the desalination process and fresh water storage. Passengers in vehicles passing over the bridge are able to see the water and energy systems on display to help visually embed the water system in the public conscience.

\section{PROJECT PHASING AND TIMELINE}

Given the scale and the scope of the overall project, a phased deployment of the infrastructure is necessary (Fig. 10). However, the decentralized nature of the system makes incremental activation and operation of pieces of the system possible even during a phased construction process. Individual municipalities could begin work on building the pieces of the infrastructure that fall within their territories. As the mainland China territory of the Pearl River Delta region approaches the a more complete political unification with Hong Kong and Macau in 2047 and 2049, the wastewater and water supply loops could begin to close. A fully connected water interchange could be in place by the year 2050.

\section{CONCLUSIONS AND OPPORTUNITIES}

A strategy for piggybacking a water resource loop onto existing vehicular networks could pave a path for weaving other types of connective infrastructure together as the PRD continues to transform and develop. If designed with care and attention, the PRD SEA loop could attract a wealth of public amenities and investment opportunities.
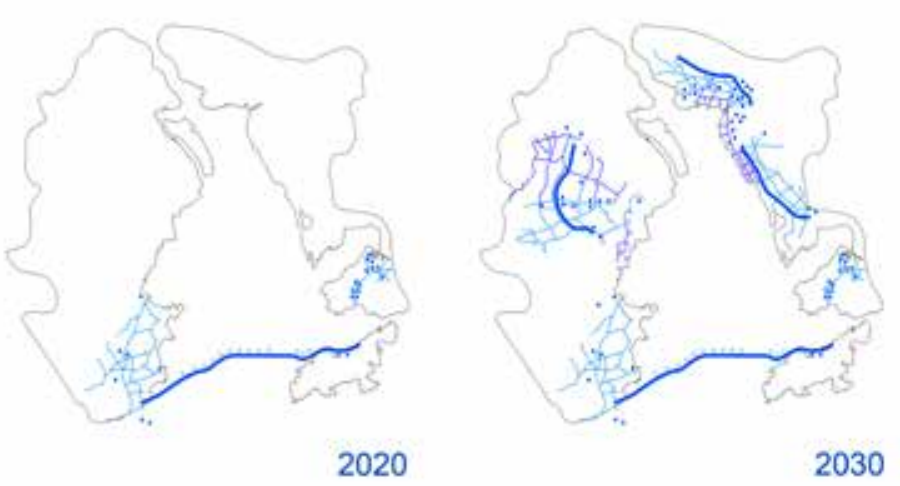
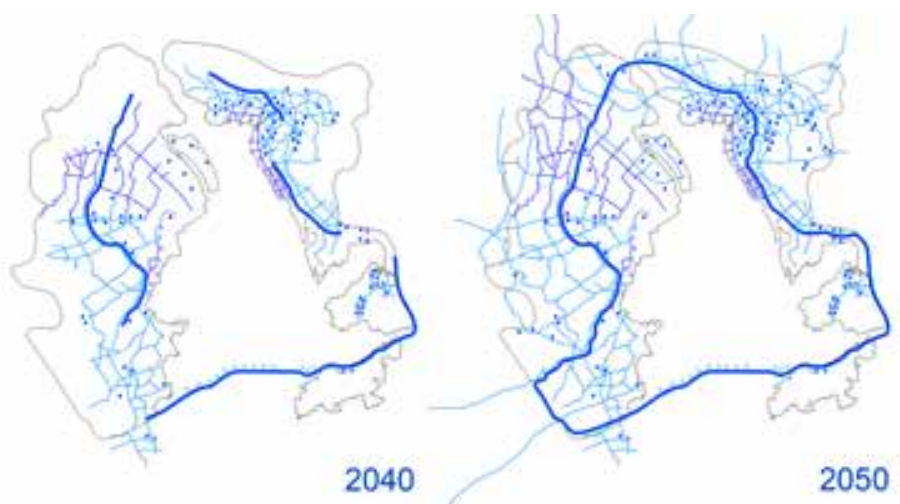

Figure 10. A phasing diagram of how the Pearl River Delta Special Ecological Area water resource loop may be developed over the coming decades. 
Projects like New York City's High Line is an example of a reconditioned piece of defunct infrastructure that has paid for its initial investment multiple times over when considering the extreme increase in value of the real estate market it has generated and the leisure and cultural amenities it has attracted in the years since its redevelopment. The first phase of the High Line, a $1.5 \mathrm{mi}$. long [2,4 km] linear park that runs on a raised viaduct through New York City's Chelsea and Meatpacking District neighborhoods, used $\$ 152$ million in public funding and more than $\$ 300$ million in private donations. ${ }^{2}$ It draws more than six million visitors per year and has established itself as one of New York's premiere tourist attractions. The High Line's economic impact on its surrounding neighborhoods has been profound. To gain support for the park from property owners, the city created a special zoning district that allowed property owners to sell their air rights above the High Line to be reallocated to selected areas within the neighborhood, allowing densification of the area surrounding the park and justifying the city's investment. The New York City Planning Department in 2011 estimated that twenty-nine new projects built since 2006 around the High Line accounted for 2,558 residential units, one thousand hotel rooms, and $423,000 \mathrm{sq}$. $\mathrm{ft}$. [39.298 $\mathrm{m}^{2}$ ] of office space and drew more than $\$ 2$ billion in private investment and twelve thousand new jobs. ${ }^{3}$ One study calculated that the High Line increased property tax receipts within one-third of a mi. [536 m] of the park by $\$ 100$ million in 2010 , nearly repaying the city's investment in just one year. ${ }^{4}$

Another precedent is the Atlanta BeltLine, an ambitious project to build a $22 \mathrm{mi}$. loop [35 km] of rail transportation, $33 \mathrm{mi}$. [53 km] of multiuse trails, and 1,300 acres [526 ha] of parks on (mostly) abandoned railways surrounding the core of Atlanta, Georgia over 25 years. ${ }^{5}$ When complete, this so-called "Emerald Necklace" (borrowing a term from Frederick Law Olmsted) will connect forty-two neighborhoods through high-quality public

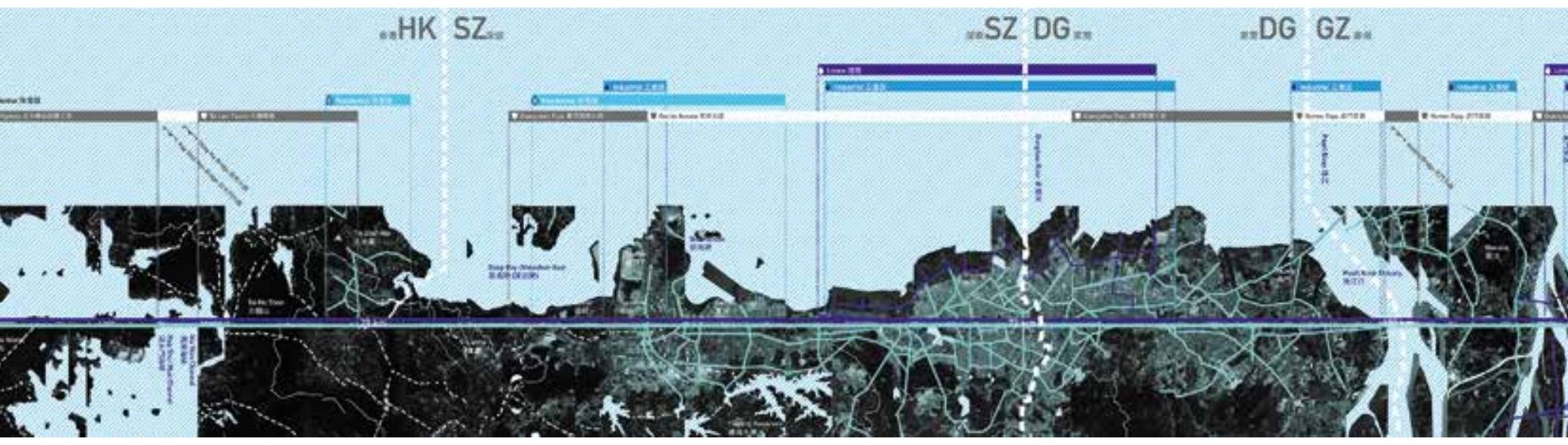

Figure 11. An unwrapped, linear drawing of the Pearl River Delta and Pearl River Delta Special Ecological Area loop that visually reconstructs the urban geography in relation to the new infrastructural loop. The drawing reimagines actual political and geographical boundaries around ecological connections. 
transportation and $20 \mathrm{ft}$. wide [6 m] pedestrian and bicycle superhighways.

First proposed in a 1999 graduate thesis by Georgia Tech student

Ryan Gravel, the project broke ground in 2006 after an extensive public engagement and planning process, and the first trail section of the project opened in 2008. The initial portions of the project were funded using a special tax-allocation district agreement between the City of Atlanta, Atlanta Public Schools, and Fulton County, wherein the jurisdictions agreed to dedicate future property tax revenue increases along the BeltLine corridor over the next 25 years to construction on the BeltLine. In 2016, Atlanta voters approved a sales tax referendum worth an estimated $\$ 2.5$ billion over the next 40 years to fund public transportation, including $\$ 66$ million to complete the BeltLine. Although to date only a few stretches of the multiuse trail portion of the project are complete, the project is already having a large economic impact on surrounding neighborhoods. Since 2005, more than fifty projects and $\$ 1$ billion in private investment have taken place in the BeltLine corridor. ${ }^{6}$ As with the High Line, however, critics of the BeltLine point to displacement of low-income residents associated with rising land values as a sign that the economic gains realized by the BeltLine are not universally enjoyed across the economic spectrum. ${ }^{7}$

In addition to potable and wastewater facilities, the loop could also host and link recreational zones, nature preserves and critical habitats for migratory species. Bicycle, walking and hiking paths could be integrated to link communities on all sides of the delta. Increased residential development along the loop could take advantage of potable water sources and wastewater treatment possibilities while positively affecting the value of land and quality of life for residents.

Maintenance is a challenge for cross-boundary infrastructures, but the PRD SEA could be managed in a similar way to transportation infrastructure between states and municipalities. Interdependent organizational entities

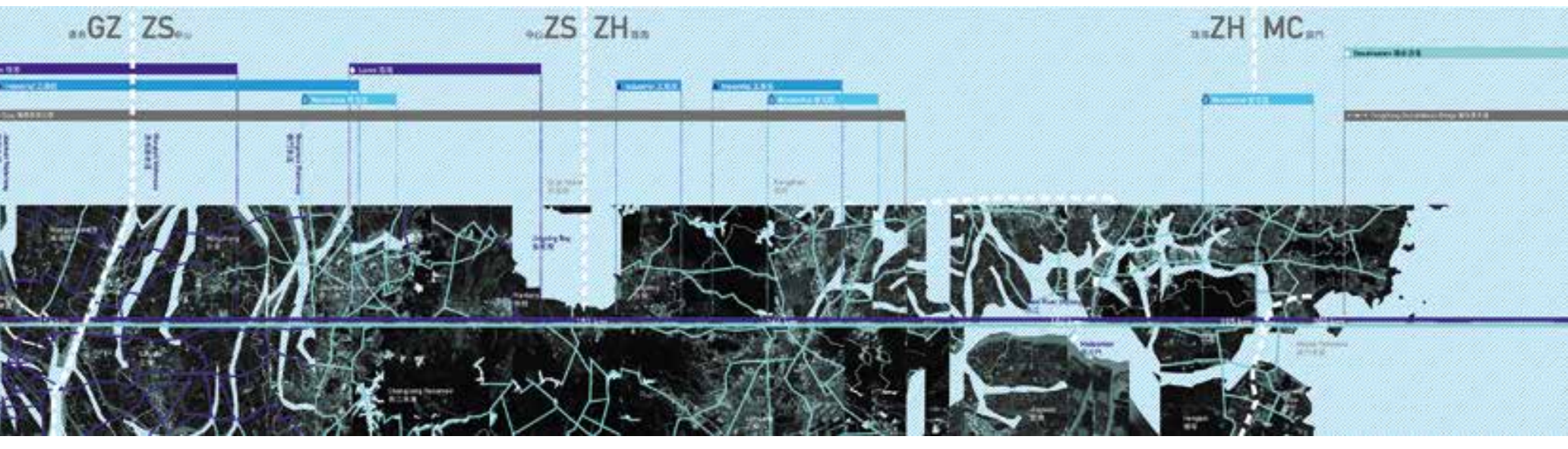


like port authorities, interstate highway departments, energy grids and rail networks could provide managerial and institutional models for an SEA loop. The fact that China generally controls and will eventually totally control most of the territory in the PRD is beneficial in this delta scenario. Transportation links that are presently under development such as the Hong Kong-Zhuhai-Macau Bridge and Beijing-Guangzhou-Hong Kong high-speed railway (Jingguangshengang Railway) are evidence that separate administrative entities in the PRD region are capable of cooperation when there are future economic gains to be created. The scope of other projects in mainland China such as the Three Gorges Dam or the New Silk Road demonstrate the nation's willingness to take on huge engineering projects in the name of long term growth and development. Ultimately, the project proposes to obscure political boundaries in favor of ecological ones. An unfolded delta network diagram (Fig. 11) visualizes the PRD SEA fresh water and treated wastewater loop as a linear form. It highlights border crossings, water bodies, and reconstructs the urban geography in relation to the new infrastructural loop. In doing so, the delta is understood as a continuous network organized around shared water resources, rather than a series of zones divided by political and geographical boundaries.

With the introduction of a shared water infrastructure, the political and economic relationships between the municipalities and special administrative regions along the PRD SEA become more sophisticated in their capacity for exchange. As of now, the Special Administrative Regions of Hong Kong and Macau are creating demand for potable water in a unidirectional resource supply chain. The multilateral exchange of valuable potable water for re-valued wastewater would lead to a more equitable resource trade platform for the various political constituents.

\section{Notes}

1. Dorothy Tang, "Engineered Waters of Hong Kong and Shenzhen." Landscape Architecture Frontiers 1.1 (2013): 55-67.

2. Kate Ascher and Sabina Uffer, "The High Line Effect" (paper presented at the Council on Tall Buildings and Urban Habitat, New York, NY, October 2015: 227).

3. Patrick McGeehan, “The High Line Isn't Just a Sight to See; It's Also an Economic

Dynamo," The New York Times, June 5, 2011.

4. Michael Levere, "The High Line Park and Timing of Capitalization of Public Goods" (working paper, University of California San Diego, Department of Economics, La Jolla CA, USA, 2014).

5. "Atlanta BeltLine Overview," Atlanta BeltLine,

https://beltline.org/about/the-atlanta-beltline-project/atlanta-beltline-overview/.

6. "A Catalyst for Urban Growth and Renewal," Atlanta BeltLine, http://beltline.org/progress/progress/economic-development-progress/.

7. Dan Immergluck, "Large Redevelopment Initiatives, Housing Values and Gentrification: The Case of the Atlanta Beltline," Urban Studies 46, no. 8 (2009): 1723-45. 


\section{Acknowledgments}

Together Carlow, Valin and Al collaborated on the research and design of the PRD SEA project for the 2011 Shenzhen and Hong Kong Bi-City Biennale of Urbanism/Architecture.

\section{Credits}

All figures provided by the Author.

\section{PROJECT CREDITS}

Design Team: Stefan Al, Jason Carlow, Ivan Valin

Project Consultants: Iris Hwang (Arup), Rowan Roderick-Jones (Arup - Hong Kong),

Kenneth Kwok (Arup - Hong Kong), Kam-Shing Leung (Arup - Hong Kong)

Project Collaborators: Anthony Lam, Daniel Fung, Peter Lampard

Project Contributors: Audrey Ma, Norman Ung, Dannes Kok, Frederick Li

Jason Carlow holds a degree in Visual and Environmental Studies from Harvard University and a Master of Architecture from Yale University. His recent work focuses on using digitally driven design and production as a lens to investigate high-rise building typologies, building component systems and the relationship between architecture and infrastructure. He is currently an Assistant Professor of Architecture at the American University of Sharjah in the United Arab Emirates. E-mail: jasoncarlow@gmail.com

Ivan Valin is an Assistant Professor of Landscape Architecture in the Faculty of Architecture at the University of Hong Kong. His research examines alternative paradigms for nature in the city, specifically looking at the histories, forms, and impacts of landscape systems in the urbanized tropics. Ivan has more than ten years in professional practice in the fields of landscape architecture and architecture and is a founding partner of VALECHE Studio, a research and design consultancy based in Hong Kong. E-mail: ivalin@hku.hk

Stefan Al is an architect, author, and an Associate Professor of Urban Design at the University of Pennsylvania. Al has worked as a practicing architect on renowned projects such as the Canton Tower in Guangzhou. He has also served as an advisor to the Hong Kong government (consulting on the development of the city's harbor), the Chinese government (advising on new urban design guidelines), and the United Nations High-Level Political Forum on Sustainable Development. E-mail: stefan@stefanal.com 